\title{
Isolation of a contact-dependent haemolysin from Mycobacterium tuberculosis
}

\author{
R. G. DESHPANDE, M. B. KHAN, D. A. BHAT and R. G. NAVALKAR
}

Department of Microbiology and Immunology, Morehouse School of Medicine, 720 Westview Drive, Atlanta, GA 30310, USA

\begin{abstract}
Contact-dependent haemolytic activity was observed with cells of Mycobacterium tuberculosis $\mathrm{H}_{37} \mathrm{Rv}$ and $M$. tuberculosis $\mathrm{H}_{37} \mathrm{Ra}$, but not with those of $M$. bovis, $M$. bovis BCG and $M$. africanum. Culture filtrates of all these strains did not exhibit any haemolytic activity. M. tuberculosis $H_{37} R v$ was subsequently used for the isolation of haemolysin. Haemolytic activity was retained in the cell debris even after sonication of the cells and treatment with Tween 80 and lysozyme. Solubilisation of haemolysin was possible only after the cell debris was washed with ethanol $70 \%$ and then treated with Tween $800.1 \%$. The haemolysin thus obtained showed a micellar $M_{r}$ of $>200000$ by gelfiltration on Sephadex G-200 and a subunit $M_{r}$ of 66000 by SDS-PAGE. It was sensitive to trypsin but stable when heated at $60^{\circ} \mathrm{C}$ for $10 \mathrm{~min}$. Polyclonal serum raised in rabbits against the haemolysin neutralised the haemolytic activity. The $\mathrm{N}$-terminal amino-acid sequence of the 66-kDa subunit of haemolysin showed identity with TB66, the 66-kDa secretory protein of $M$. tuberculosis, and $30 \%$ homology with the haemolysin $A$ precursor of Vibrio cholerae. Phosphatidylglycerol inhibited lysis of sheep erythrocytes by the haemolysin and is probably the receptor for the haemolysin. Haemolysin not only lysed erythrocytes, but was also cytotoxic to human lung cells. It appears that, among the members of the $M$. tuberculosis complex, the cell-bound contact-dependent haemolysin/cytolysin is restricted to $M$. tuberculosis and it may be associated with the pathogenesis of $M$. tuberculosis.
\end{abstract}

\section{Introduction}

Tuberculosis is by far the most prevalent infectious disease worldwide. Because of recent increases in cases of tuberculosis, considerable attention has been devoted to the development of improved drugs and vaccines against the disease as well as diagnostic methods with greater sensitivity and specificity. Part of the solution to better control of tuberculosis may rely on a better understanding of the biology of infection of mammalian cells by the bacilli. To produce disease, successful intracellular pathogens like Mycobacterium tuberculosis must evade the host cell's mechanism of killing. It is unclear which strategies $M$. tuberculosis uses to survive inside the host cell.

Soluble and membrane-bound cytolysins have been known to play an important role in the ability of

Received 10 June 1996; accepted 14 Aug. 1996. Corresponding author: Professor R. G. Navalkar. intracellular bacterial pathogens to enter, replicate within, and exit from host cells [1,2]. A membranebound cytolysin has been implicated in the escape from phagosomes and intracellular growth of Shigella flexneri [3]. Studies of bacterial pathogens have shown that soluble and membrane-bound cytolysins are important virulence factors. For example, strains of Escherichia coli expressing the $\alpha$-haemolysin are $10-$ 1000 -fold more virulent in animal models than strains lacking $\alpha$-hemolysin [4]. Listeriolysin $O$ has been shown to be necessary for virulence of Listeria monocytogenes [1]. King et al. have reported the presence of contact-dependent cytolytic activity in $M$. tuberculosis and speculated on its role in the pathogenesis of the organism [5]. However, the haemolysin/cytolysin of $M$. tuberculosis was not isolated by these investigators. The pathogenic role of haemolytic activity in disease caused by rapidly growing mycobacteria has also been discussed by Udou [6]. This study reports the presence, isolation and characterisation of a cell-bound contact-dependent haemolysin/cytolysin of $M$. tuberculosis. 


\section{Materials and methods}

Preparation of cells, cell sonicate, culture filtrate and extracts

M. tuberculosis $\mathrm{H}_{37} \mathrm{Rv}$ ATCC 25618, M. tuberculosis $\mathrm{H}_{37} \mathrm{Ra}$ ATCC 25177 , M. bovis ATCC 35740 , M. bovis BCG Copenhagen and M. africanum ATCC 25420 were grown with shaking for $4-6$ weeks at $37^{\circ} \mathrm{C}$ in Middlebrook 7H9 Broth (Difco) containing glycerol without ADC enrichment. The cells were harvested by centrifugation, washed and resuspended in $0.1 \mathrm{M}$ phosphate-buffered saline, $\mathrm{pH} 7.2$ (PBS). The culture filtrate (CF) was sterilised by passing through a $0.45-\mu \mathrm{m}$ membrane filter, concentrated, and tested for haemolytic activity. In addition, cells of $M$. tuberculosis $\mathrm{H}_{37} \mathrm{Rv}$ in $0.01 \mathrm{M}$ PBS $(\mathrm{pH} 7.2)$ were sonicated in ice for six cycles each of $4 \mathrm{~min}$ on a W-375 sonicator (Heat Systems-Ultrasonics, Plainview, NY, USA) with a $100-$ $\mathrm{W}$ energy output and centrifuged at $8000 \mathrm{~g}$ for $30 \mathrm{~min}$. The resultant supernate was termed cell sonicate (CS). The cell debris was incubated overnight at $28^{\circ} \mathrm{C}$ with PBS containing Tween- $800.1 \%$ (PBST) and $1 \mathrm{mg}$ of lysozyme. The supernate after centrifugation $(8000 \mathrm{~g}$ for $30 \mathrm{~min}$ ) was termed Tween extract (TE). The debris was washed with ethanol $70 \%$ and incubated in PBST for $3 \mathrm{~h}$ at $28^{\circ} \mathrm{C}$. The supernate after centrifugation at $8000 \mathrm{~g}$ for $30 \mathrm{~min}$ was termed haemolytic extract (HE).

\section{Assay for haemolytic activity}

Concentrated CFs of all the organisms and the CS, TE and $\mathrm{HE}$ of $M$. tuberculosis $\mathrm{H}_{37} \mathrm{RV}(0.5 \mathrm{ml})$ were tested for haemolytic activity as described previously [6]. Cells were screened for contact-dependent lysis of sheep erythrocytes as described previously [5]. One $\mathrm{ml}$ of bacilli suspended in PBS $\left(10^{10} / \mathrm{ml}\right)$ was mixed with $1 \mathrm{ml}$ of sheep red blood cells (RBCs) $0.7 \%$ in PBS containing bovine serum albumin $0.5 \%$, co-sedimented by centrifugation at $8000 \mathrm{~g}$ for $10 \mathrm{~min}$, and were then incubated at $37^{\circ} \mathrm{C}$ for $12-16 \mathrm{~h}$. The haemolytic activity of CF, CS, TE and HE $(0.5 \mathrm{ml}$ each) was examined in the same way. The samples were then centrifuged ( $8000 \mathrm{~g}$ for $30 \mathrm{~min}$ ) and the $\mathrm{A}_{540}$ of the supernates was measured as an indication of cell lysis and release of haemoglobin. Appropriate controls (RBCs and $7 \mathrm{H} 9$ broth or PBST) were included. A sheep RBC $0.7 \%$ suspension, incubated under similar conditions to experimental samples, was centrifuged $(8000 \mathrm{~g}$ for $30 \mathrm{~min}$ ) and the supernate was used as the blank.

\section{Heat and trypsin stability}

Samples of HE $(0.5 \mathrm{ml}$ each) with known activity $\left(\mathrm{A}_{540}=0.7\right)$ were heated at $40^{\circ} \mathrm{C}, 50^{\circ} \mathrm{C}, 60^{\circ} \mathrm{C}$ and $70^{\circ} \mathrm{C}$ for $10 \mathrm{~min}$, cooled and the haemolytic activity was then assayed as described above. The trypsin susceptibility of $\mathrm{HE}$ was investigated by adding $0.5 \mathrm{ml}$ of the HE to $0.1 \mathrm{ml}$ of a solution of trypsin (bovine pancreas, type III; Sigma) $1 \mathrm{mg} / \mathrm{ml}$ in PBS. After incubation at $37^{\circ} \mathrm{C}$ for $30 \mathrm{~min}$, the sample was assayed for haemolytic activity. As enzyme control, $0.1 \mathrm{ml}$ of trypsin solution was added to RBCs. Unheated $\mathrm{HE}(0.5 \mathrm{ml})$ that was not treated with trypsin was used as a positive control.

\section{Determination of molecular weight $\left(M_{r}\right)$ by Sephadex G-200 gel filtration}

The $\mathrm{M}_{\mathrm{r}}$ of haemolysin was determined by Sephadex G200 (Pharmacia) gel filtration of HE with $0.05 \mathrm{M}$ potassium phosphate buffer, $\mathrm{pH} 6.8$, containing $0.1 \mathrm{M}$ $\mathrm{NaCl}$. Gel filtration markers (Sigma; $\mathrm{M}_{\mathrm{r}} 12000-$ 200000 ) in this buffer were used to calibrate the column. HE $(2 \mathrm{ml})$ was loaded on the column $(30 \times 2.5 \mathrm{~cm})$. Fractions $(2 \mathrm{ml})$ were collected and checked for the presence of protein by $\mathrm{A}_{280}$ measurements. The haemolytic activity of the protein-containing fractions was determined and they were subjected to electrophoresis on SDS-polyacrylamide $(12 \%)$ gels and silver staining.

\section{Amino-acid terminal sequencing}

The $66-\mathrm{kDa}$ subunit of haemolysin was transferred electrophoretically from the SDS-PAGE gel to a polyvinylidine difluoride membrane $(0.2-\mu \mathrm{m}$ pore; BioRad) at a constant current of $270 \mathrm{~mA}$ for $90 \mathrm{~min}$. The membrane was stained for $1 \mathrm{~min}$ in Coomassie Blue, briefly destained in methanol $40 \%$ and acetic acid $10 \%$ in water, washed in distilled water and airdried. Protein was cut from the membrane, and aminoacid terminal sequencing was performed by Dr J. Pohl, Emory University, Atlanta, GA, USA. Search of the Swiss-Prot 28 and PIR 39 databanks (Fast DB, release 5.4) was conducted to determine sequence homology.

\section{Western blotting}

HE and TB66, a secretory 66-kDa protein of $M$. tuberculosis [7], were transferred electrophoretically from an SDS-PAGE $12 \%$ gel to a nitrocellulose membrane $(0.2-\mu \mathrm{m}$ pore size; BioRad) by the method of Towbin et al. [8]. Monoclonal antibody (MAb) OD4AG3 which recognises TB66, was used as the primary antibody. Peroxidase-conjugated rabbit antimouse polyvalent immunoglobulin (BioRad) was used as the secondary antibody. The reaction was visualised with 4-chloro-1-naphthol and $\mathrm{H}_{2} \mathrm{O}_{2}$ as the substrate.

\section{Polyclonal antiserum to haemolysin}

Antibodies to haemolysin were raised in three rabbits by administering four weekly subcutaneous injections each consisting of a 1:1 v:v mixture of HE ( $100 \mu \mathrm{g}$ of protein) and Freund's incomplete adjuvant (Difco). One week after the last injection, the rabbits were bled and the serum was checked for the presence of antibodies to HE by ELISA. The sera showing the presence of antibodies to haemolysin were pooled, heated at $56^{\circ} \mathrm{C}$ to inactivate the complement, and stored at $-20^{\circ} \mathrm{C}$. 


\section{Neutralisation of haemolytic activity}

Neutralisation of haemolytic activity by polyclonal anti-haemolysin serum and MAb OD4AG3 was examined by incubating $0.5 \mathrm{ml}$ of $\mathrm{HE}$ (of known haemolytic activity) with $0.05 \mathrm{ml}$ of appropriately diluted antiserum or $\mathrm{MAb}$ at $37^{\circ} \mathrm{C}$ overnight. As control, HE $(0.5 \mathrm{ml})$ was incubated with $0.05 \mathrm{ml}$ of diluted normal rabbit serum (NRS) under identical conditions. Two $\mathrm{ml}$ of a sheep RBC $(0.7 \%)$ suspension were added and incubation continued overnight at $37^{\circ} \mathrm{C}$. After centrifugation ( $8000 \mathrm{~g}$ for $30 \mathrm{~min}$ ), haemolytic activity was determined by measuring the $A_{540}$ of the supernates.

\section{Cytotoxicity assay}

The human lung pneumocyte A549 cell line (CCL 185) was obtained from the American Type Culture Collection. The cells were maintained in six-well tissue culture dishes as confluent monolayers in RPMI 1640 (Sigma) containing fetal bovine serum (Sigma) $10 \%$ at $37^{\circ} \mathrm{C}$ in $\mathrm{CO}_{2} 5 \%$ in air with weekly passage and feedings every 3-4 days. HE and the haemolytic G-200 fractions were tested for cytotoxicity. PBS-Tween was used as a control. HE and the Sephadex G-200 fractions (each containing $c .10 \mu \mathrm{g}$ of protein) were added individually to wells containing monolayers. The monolayers were incubated at $37^{\circ} \mathrm{C}$ and observed for changes at $2 \mathrm{~h}, 6 \mathrm{~h}, 24 \mathrm{~h}$ and over a few days. Cytotoxicity was determined by visual inspection of the monolayers with an inverted microscope and by comparison with monolayers incubated with PBST.

\section{Inhibition of haemolytic activity}

Different lipids (from Sigma) that constitute the RBC membrane (phosphatidylglycerol, phosphorylcholine, phosphatidylinositol, cholesterol, sphingomyelin and phosphatidylethanolamine) were used at a final concentration of 200,100 and $50 \mu \mathrm{M}$ to determine if any inhibited the haemolytic activity of HE. Each of these lipids was first mixed with sheep RBCs, to which HE $0.5 \mathrm{ml}$ was then added. The positive control contained $0.5 \mathrm{ml}$ of $\mathrm{HE}$ and RBCs without any lipid. The tubes were incubated at $37^{\circ} \mathrm{C}$ overnight and checked for the presence or absence of haemolysis.

\section{Results}

Cells of M. tuberculosis $\mathrm{H}_{37} \mathrm{Rv}$ showed strong contactdependent haemolysis of sheep RBCs $\left(\mathrm{A}_{540}=0.6\right)$. M. tuberculosis $\mathrm{H}_{37} \mathrm{Ra}$ cells similarly showed contactdependent haemolysis $\left(\mathrm{A}_{540}=0.45\right)$. However, no haemolytic activity was demonstrated by $\mathrm{CF}$ of these strains $\left(A_{540}=0.12\right)$ as compared with the $7 \mathrm{H} 9$ broth control $\left(\mathrm{A}_{540}=0.13\right)$. No haemolysis was demonstrated by the cells or the CF of $M$. bovis, M. bovis BCG and M. africanum $\left(\mathrm{A}_{540}=0.1\right)$. Neither sonication of the M. tuberculosis cells nor the Tween-lysozyme treatment of the sonicated cells released the haemolytic activity

of M. tuberculosis; i.e., CS and TE did not show any haemolytic activity $\left(\mathrm{A}_{540}=0.09\right)$ as compared with the control RBCs $\left(\mathrm{A}_{540}=0.06\right)$. Solubilisation of haemolysin could not be achieved even with $8 \mathrm{M}$ urea. Haemolytic activity was retained in the cell debris that was obtained after sonication and Tween-lysozyme treatment $\left(\mathrm{A}_{540}=0.8\right)$. HE obtained after ethanol treatment of this debris showed strong haemolytic activity $\left(\mathrm{A}_{540}=0.7\right)$.

SDS-PAGE and silver staining of HE showed a prominent band with $\mathrm{M}_{\mathrm{r}}$ of c. 66000 (Fig. 1). Gel filtration chromatography of HE on G-200 yielded a single protein-containing peak of c. $200 \mathrm{kDa}$ in two or three fractions, which, when pooled, showed strong haemolytic activity $\left(\mathrm{A}_{540}\right.$ of $0.5 \mathrm{ml}$ of pooled fractions $=0.4$ ). Silver staining of this pooled fraction after SDS-PAGE showed a single band of $c .66 \mathrm{kDa}$ (Fig. 1). The N-terminal amino-acid sequence of the $66-\mathrm{kDa}$ subunit of haemolysin was asp-lys-hislys-ser-glu-ile-ala-his-arg-phe-lys-asp-leu-gly-glu-gluhis-phe-lys. It was identical to that of TB66 [7] and it showed $30 \%$ homology with the haemolysin A

a

$\mathrm{kDa}$

$97.4-$

$66.2-$

$43.0-$

31.0

$21.5-$

\section{$14.4-$}

Fig. 1. SDS-PAGE (12\%) and silver staining of: a, HE; $\mathbf{b}$, haemolytic G-200 fraction of $M$. tuberculosis $\mathrm{H}_{37} \mathrm{Rv}$. The left lane contains the mol.wt markers $(\mathrm{kDa})$ (top to bottom: phosphorylase b 97.4; BSA 66.2 ; ovalbumin 43; carbonic anhydrase 31 ; soybean trypsin inhibitor 21.5; lysozyme 14.4). 
precursor of Vibrio cholerae. On Western blotting, $\mathrm{MAb}$ OD4AG3 that recognises TB66, a $66-\mathrm{kDa}$ protein of $M$. tuberculosis [7], also reacted with $\mathrm{HE}$ and the haemolytic G-200 fraction (Fig. 2). In ELISA, MAb OD4AG3 showed weaker reactivity with $1 \mu \mathrm{g}$ of haemolysin $\left(\mathrm{A}_{492}=0.3\right)$ than with $1 \mu \mathrm{g}$ of TB66 $\left(\mathrm{A}_{492}=0.6\right)$. Polyclonal anti-haemolysin serum, on the other hand, showed similar reactivity with both haemolysin $\left(\mathrm{A}_{492}=0.8\right)$ and $\mathrm{TB} 66 \quad\left(\mathrm{~A}_{492}=0.75\right)$. TB66 isolated in this laboratory from the CF of $M$. tuberculosis by Ni-NTA chromatography [7] did not show any haemolytic activity. Therefore, the binding of haemolysin to Ni-NTA resin (Qiagen, Chatsworth, CA, USA) was determined by loading $\mathrm{HE}$ on $1 \mathrm{ml}$ of Ni-NTA resin and performing immobilised metal affinity chromatography (IMAC) as described earlier for the isolation of TB66 [7]. However, HE did not
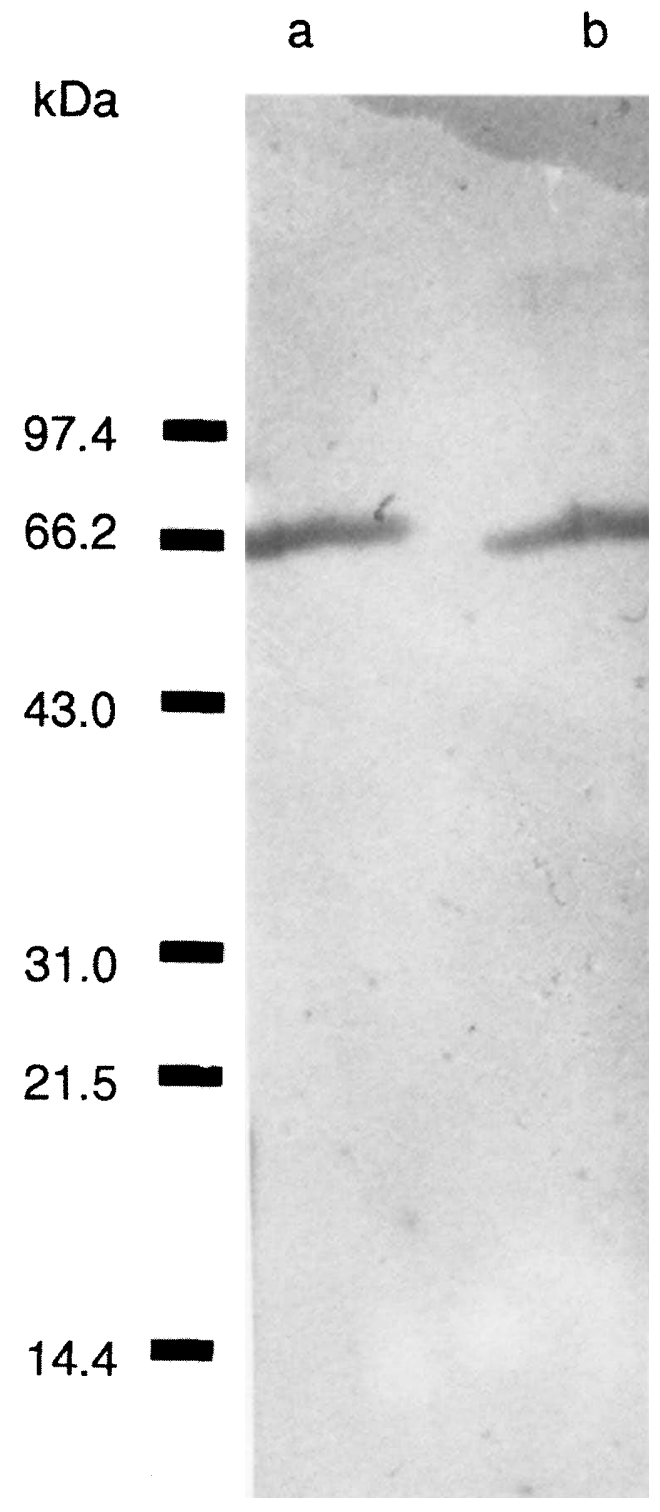

Fig. 2. Immunoblot of: a, HE; b, haemolytic G-200 fraction of $M$. tuberculosis $\mathrm{H}_{37} \mathrm{RV}$ with MAb OD4AG3. The left lane shows the positions of blotted mol.wt markers (see Fig. 1). bind to the Ni-NTA resin and all haemolytic activity was obtained in the flow-through.

Heating $\mathrm{HE}$ at $60^{\circ} \mathrm{C}$ for $10 \mathrm{~min}$ did not destroy the activity $\left(\mathrm{A}_{540}=0.65\right)$. However, heating $\mathrm{HE}$ at $70^{\circ} \mathrm{C}$ produced a significant decrease in haemolytic activity $\left(\mathrm{A}_{540}=0.3\right)$. Trypsin-treated HE showed no detectable haemolytic activity $\left(\mathrm{A}_{540}=0.1\right)$. Haemolytic activity of $\mathrm{HE}$ was also significantly inhibited by addition of $50 \mu \mathrm{M}$ phosphatidylglycerol $\left(\mathrm{A}_{540}=0.2\right)$ as compared to $\mathrm{HE}$ without any lipid $\left(\mathrm{A}_{540}=0.7\right)$. However, the other lipids used in this study, even at $200 \mu \mathrm{M}$, did not cause any significant inhibition of haemolytic activity. Haemolytic activity was neutralised by incubation of $\mathrm{HE}$ with polyclonal anti-haemolysin serum $\left(\mathrm{A}_{540}=\right.$ 0.2 ) as compared to $\mathrm{HE}$ incubated with normal rabbit serum $\left(A_{540}=0.6\right)$. No effect on haemolytic activity was observed when $\mathrm{HE}$ was incubated with $\mathrm{MAb}$ OD4AG3 $\left(\mathrm{A}_{540}=0.6\right)$.

No cytotoxic effect was observed when human lung cells were incubated with PBST (Fig. 3a). However, monolayer destruction was evident after overnight incubation with $\mathrm{HE}$ or the haemolytic G-200 fraction (Figs. $3 \mathrm{~b}$ and c). The cytotoxic phenotype was observed as early as $2 \mathrm{~h}$ of incubation and was characterised by the detachment of cells. After incubation for $24 \mathrm{~h}$, large areas of the monolayer were detached leaving large plaques as seen in Figs. $3 b$ and $c$. The detached dead cells then formed large floating aggregates in the culture fluid as incubation continued. The monolayers from control cultures treated with PBST were confluent even after incubation for 9 days.

\section{Discussion}

M. tuberculosis cells demonstrated strong contactdependent cell-associated haemolytic and cytolytic activity that is either not expressed or expressed below detectable levels in other members of the $M$. tuberculosis complex. The cell-associated haemolysin from $M$. tuberculosis $\mathrm{H}_{37} \mathrm{RV}$ was successfully isolated and characterised. The $\mathrm{M}_{\mathrm{r}}$ and N-terminal amino-acid sequence of haemolysin were identical to TB66, a 66$\mathrm{kDa}$ secretory protein of $M$. tuberculosis [7]. Both TB66 and haemolysin were recognised by polyclonal anti-haemolysin serum and MAb OD4AG3. Polyclonal serum inhibited haemolytic activity whereas $\mathrm{MAb}$ OD4AG3 did not. MAb OD4AG3 had a lower affinity for haemolysin than TB66. TB66 bound to Ni-NTA resin [7] whereas haemolysin demonstrated only negligible binding to Ni-NTA. Therefore we postulate that haemolysin is secreted into the medium as TB66 which undergoes a conformational change and a subsequent loss of haemolytic activity. The presence of an inactive precursor and an active haemolysin with a similar $\mathrm{N}$ terminal amino-acid sequence has been reported for aerolysin of Aeromonas hydrophila [9]. Different 

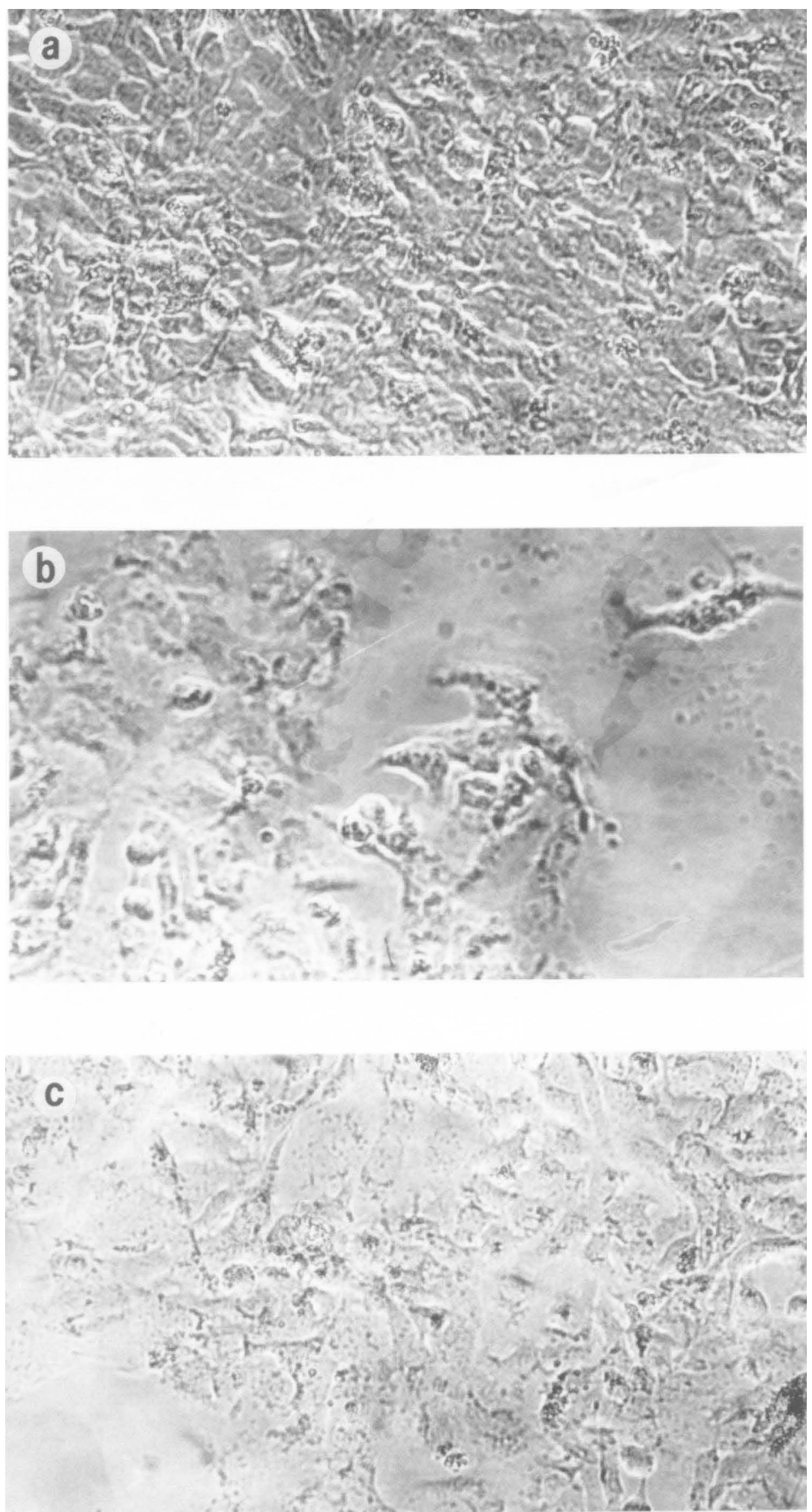

Fig. 3. Cytotoxicity studies: human lung cell line after overnight incubation with: a, PBST; b, HE; c, haemolytic G-200 fraction. 
conformations of the active and inactive form of haemolysin have been reported in Serratia marcescens $[10]$.

The exact location of the haemolysin within the cell is not known. The difficulty in its solubilisation suggests that it is an integral membrane protein which can be extracted only after disruption of the lipid bilayer by ethanol. Detergents, alone or in combination with a denaturing agent such as urea, were unable to solubilise it. The haemolysin of $M$. tuberculosis appears to be a very stable enzyme which retains its activity even after treatment with denaturing agents, detergents and organic solvents. The purification procedure used here removed most of the cellular, cytoplasmic and membrane proteins in the Tweenextract and an almost pure preparation of haemolysin was obtained in HE. Although insolubility presents difficulties in purification, it is generally recognised that insoluble antigens evoke a better immune response than soluble antigens [11].

A species-specific nucleotide sequence of $M$. tuberculosis has been isolated by Leão et al. [12] which when expressed in E. coli encoded a protein (HL-A) exhibiting haemolytic activity. This fragment is different from the one isolated by King et al. [5] from $M$. tuberculosis that encoded cytolytic activity. The deduced amino-acid sequence of HL-A showed 58\% similarity with phospholipase C (PLC) of Pseudomonas aeruginosa and its expression in $E$. coli produced $\beta$-haemolysis suggestive of phospholipase activity [12]. No sequence similarity was observed between the amino-acid sequence of HL-A (predicted $M_{r} c$. 56000 ) and the N-terminal sequence of the haemoly$\sin$ isolated in this study. The presence of HL-A or PLC activity in $M$. tuberculosis has so far not been demonstrated.

Dissemination of viable tubercle bacilli from the lung is a critical event in the establishment of $M$. tuberculosis infection. Studies [13] suggest that $M$. tuberculosis might have the ability to gain access to the host lymphatics and circulatory system by penetrating directly the alveolar epithelial lining of an infected lung. These investigators showed that $M$. tuberculosis $\mathrm{H}_{37} \mathrm{Rv}$, but not avirulent $M$. bovis BCG, is cytotoxic for cultured A549 human lung alveolar epithelial cells and suggested that cytotoxicity for lung epithelial cells is a virulence-associated phenotype of M. tuberculosis [13]. The present study demonstrated that haemolysin/cytolysin is produced by $M$. tuberculosis $\mathrm{H}_{37} \mathrm{Rv}$ and $\mathrm{H}_{37} \mathrm{Ra}$ but not by $M$. bovis and $M$. bovis BCG. It is possible that haemolysin, by virtue of its cytotoxic effect on lung epithelial cells, has a role to play in the virulence of $M$. tuberculosis.

It has been suggested that in other bacteria cytolysins play a role in processes such as invasion or entry into eukaryotic cells, intracellular multiplication, cell to cell spread, or escape from membrane-bound vacuoles or cells [14]. The possible roles of cytolysins in pathogenesis are not limited simply to the lysis of membranes. Even in the absence of lysis, bacterial cytolysins can exert profound pleiotropic effects on eukaryotic cells [2]. One possible role for the cytolytic activity of $M$. tuberculosis haemolysin may be in the release of mycobacteria from heavily laden macrophages. Because cytolysins are important virulence factors among other intracellular pathogens, further characterisation of $M$. tuberculosis haemolysin/cytolysin, the gene(s) that encodes it and its effect(s) on other host cells may provide important insights into the pathogenesis and virulence of $M$. tuberculosis.

This work was supported by the US Leprosy Panel of the US-Japan Co-operative Medical Service Program, administered by the National Institute of Allergy and Infectious Disease (Grant AI27189), and in part by the Association of Minority Health Profession Schools (AMHPS) AIDS Consortium, Minority Biomedical Research Support (MBRS GM08248) and Research Centers for Minority Institutions (NIH/NCRR No. RR03034). The authors thank Dr J. Pohl for sequencing the protein and D. Williams for the illustrations.

\section{References}

1. Cossart P, Vicente MF, Mengaud J, Baquero F, Perez-Diaz JC, Berche P. Listeriolysin $\mathrm{O}$ is essential for virulence of Listeria monocytogenes: direct evidence obtained by gene complementation. Infect Immun 1989; 57: 3629-3636.

2. Welch RA. Pore-forming cytolysins of gram-negative bacteria. Mol Microbiol 1991; 5: 521-528.

3. Sansonetti PJ, Ryter A, Clerc P, Maurelli AT, Mounier J. Multiplication of Shigella flexneri with HeLa cells: lysis of the phagocytic vacuole and plasmid-mediated contact hemolysis. Infect Immun 1986; 51: 461-469.

4. Welch RA, Falkow S. Characterization of Escherichia coli hemolysins conferring quantitative differences in virulence. Infect Immun 1984; 43: $156-160$.

5. King CH, Mundayoor S, Crawford JT, Shinnick TM. Expression of contact-dependent cytolytic activity by Mycobacterium tuberculosis and isolation of the genomic locus that encodes the activity. Infect Immun 1993; 61: 2708-2712.

6. Udou T. Extracellular hemolytic activity in rapidly growing mycobacteria. Can J Microbiol 1994; 40: 318-321.

7. Deshpande RG, Khan MB, Bhat DA, Navalkar RG. Purification and partial characterization of a novel $66-\mathrm{kDa}$ seroreactive protein of Mycobacterium tuberculosis $\mathrm{H}_{37} \mathrm{Rv}$. $J$ Med Microbiol 1994; 41: 173-178.

8. Towbin H, Staehelin T, Gordon J. Electrophoretic transfer of proteins from polyacrylamide gels to nitrocellulose sheets: procedure and some applications. Proc Natl Acad Sci USA $1979 ; 76: 4350-4354$.

9. Howard SP, Buckley JT. Activation of the hole-forming toxin aerolysin by extracellular processing. $J$ Bacteriol 1985; 163: $336-340$.

10. Braun V, Hobbie S, Ondraczek R. Serratia marcescens forms a new type of cytolysin. FEMS Microbiol Lett 1992; 100: 299-306.

11. Harlow E, Lane D. Antibodies: a laboratory manual. Cold Spring Harbor, NY, Cold Spring Harbor Laboratory. 1988: $100-102$.

12. Leão SC, Rocha CL, Murillo LA, Parra CA, Patarroyo ME. A species-specific nucleotide sequence of Mycobacterium tuberculosis encodes a protein that exhibits hemolytic activity when expressed in Escherichia coli. Infect Immun 1995; 63: 4301-4306.

13. McDonough KA, Kress Y. Cytotoxicity for lung epithelial cells is a virulence-associated phenotype of Mycobacterium tuberculosis. Infect Immun 1995; 63: 4802-4811.

14. Mims CA. The pathogenesis of infectious disease, 3rd edn. London, Academic Press. 1990. 